\title{
THE ISOLATION OF STREPTOCOCCUS PYOGENES FROM THROAT SWABS
}

\author{
P. W. Ross \\ Department of Bacteriology, University Medical School, Edinburgh EH8 9AG
}

IN a previous study, it was shown that culture of specimens of saliva from children known to habour Streptococcus pyogenes in the throat produced higher isolation rates than culture of throat swabs, which revealed the streptococci in only two-thirds of the children (Ross, 1971a). It seemed clear that swabs give an underestimate of the frequency with which $\beta$-haemolytic streptococci are associated with sore throat (BRITISH MEDICAL JOURNAL, 1972).

Hughes (1972) suggested that, because the swabs were made of buffered, absorbent, plain cotton wool, the findings might merely reflect that the swabs killed the streptococci. He argued that such swabs would be no better than a charcoal-coated type previously described by Bartlett and Hughes (1969) which were only slightly less lethal to Streptococcus pyogenes than untreated wool swabs.

Several authors have described factors that might contribute to bacterial loss or inactivation when a swab is used for sampling. It is known, for example, that the technique of swabbing is important (Mozziconacci et al., 1960; Ross, 1971b) and that the isolation rate of organisms is considerably increased if more than one swab is used. Furthermore, Dadd et al. (1970) noted that the uneven distribution of the inoculum on the swab head could affect recovery. Deleterious effects during transit on the swab include the possibility of overgrowth by commensal bacteria and the antibacterial effects of metabolic products on the significant pathogen (Hollinger and Lindberg, 1958). Some bacteria are adversely affected by excessive humidity at this stage, whereas others are sensitive to desiccation; the presence of moisture on the swab accelerated the inactivation of $\beta$-haemolytic streptococci (Rubbo and Benjamin, 1951).

There are deleterious factors directly associated with the swab or produced in it during its processing. Pollock (1948) reported that cotton wool contained antibacterial unsaturated fatty acids, and White (1965) and Mair and McSwiggan (1965) warned that certain commercially-produced swabs sterilised by $\gamma$ radiation had antibacterial properties, which Anderson (1965) attributed to the low $p \mathrm{H}$ produced in the cotton wool and not to the radiation process.

Numerous attempts have been made to overcome the deficiencies of plain cotton wool in swabs. Dipping them in serum was recommended by Rubbo and Benjamin (1951), who also found that coating swabs in egg albumen was equally effective, and by Cruickshank (1953). Bartlett and Hughes (1969) believed that the coating of plain cotton-wool swabs with bovine albumen prevented bacterial overgrowth when these swabs were used.

As an alternative to cotton wool, calcium-alginate swabs have been recommended (Cain and Steele, 1953; Ellner and Ellner, 1966), but Dadd et al. (1970) cautioned that the viability of $S$. pyogenes was rapidly lost on these. Dacron swabs have also been recommended (Hollinger and Rantz, 1959). As an answer to the deficiencies of swabs and the hazards of their transit to the laboratory, the use of transport media to increase bacterial survival has been advocated by many workers, including Pike (1945), Holmes and Lermit (1955) and Stuart (1956). There seemed to be clear parallels between the results reported by Ross

Received 17 May 1976; revised version accepted 2 Aug. 1976.

J. MED. MICROBIOL.-VOL. 10 (1977) 
(1971a) and the findings of Collee et al. (1974) whose studies on anaerobes took account of the possibility of direct toxic effects.

Accordingly, the present study had three aims: (1) to determine whether the diminished recovery of $S$. pyogenes from plain cotton-wool swabs is primarily attributable to a direct bactericidal effect; (2) to compare the isolation rates from plain cotton-wool and albumen-coated swabs, as both types of swab are widely used at present in Britain, and (3) to elucidate the mechanism of loss or inactivation of streptococci when these swabs are used.

\section{MATERIALS AND METHODS}

Sixty test strains of $S$. pyogenes freshly isolated from the throat or skin of patients in the Edinburgh Royal Infirmary were held on blood-agar plates or on blood-agar slopes in screwcapped bottles. Each was used at some time in the experiments and some more than once, on the basis of random selection. The swabs were commercially prepared by Exogen Ltd, Dumbarton Road, Scotstoun, Glasgow, and the two varieties used were plain, buffered, absorbent cotton-wool and albumen-coated non-absorbent swabs, sterilised by ethylene oxide. Plates of $5-10 \%$ human-blood agar were used, and these were incubated aerobically at $37^{\circ} \mathrm{C}$ overnight. Before plating, swabs were held at $4^{\circ} \mathrm{C}$ or room temperature $\left(17-21^{\circ} \mathrm{C}\right.$ ).

Survival of $S$. pyogenes on swabs. Simulated throat swabs were prepared as follows. One $0.02-\mathrm{ml}$ drop of a dilution of a culture of streptococci grown overnight in Todd-Hewitt broth was mixed with four drops $(0.08 \mathrm{ml})$ of pasteurised human saliva on a small standard area of the inner surface of a plastic petri dish. Control preparations were made with saline $(0.85 \% \mathrm{w} / \mathrm{v} \mathrm{NaCl})$ in place of the pasteurised saliva. The streptococcal suspension in saliva or saline was then completely taken up into the test swab. The numbers of organisms taken up by swabs throughout the series ranged from 2000-7000 but were most commonly 20004000 ; identical inocula were used in the various sections of each component experiment; numbers were calculated by performing surface viable counts from $10^{2}-10^{5}$ dilutions of the parent Todd-Hewitt broth culture by a spread-plate procedure with a sterile glass spreader. The maximum number of colonies counted in an observation generally ranged from 300-500.

Separate series of plain and albumen-coated swabs were prepared for each of 59 different strains of $S$. pyogenes. Each of these 59 series comprised four swabs, one plain swab bearing a saliva preparation, and one a saline preparation; one albumen-coated swab bearing a saliva preparation and one a saline preparation. Immediately after loading with the standardised inoculum, each of the swabs was plated four times by streaking with rotation on both halves of two blood agar plates.

Thirty experiments with 30 of the strains of $S$. pyogenes used previously were performed to compare the recovery rates of streptococci from plain and albumen-coated swabs that had been held for $4,8,24$ and $48 \mathrm{~h}$ on the bench at room temperature before plating. Identical inocula were used in each component experiment. In each of the 30 experiments, a series of four swabs (as described above) was used for each time interval. Swabs were plated out on blood agar as previously described.

Six experiments were performed, with six of the strains used previously, to compare streptococcal recovery rates from plain and albumen-coated swabs held at $4^{\circ} \mathrm{C}$ for $4,8,24$, 48 and $72 \mathrm{~h}$. In each of the six experiments, a series of four swabs (as described above) was used for each time interval.

Tests for toxicity of cotton wool. Identical inocula of $S$. pyogenes were held for $2 \mathrm{~h}$ in five sets of three-quarter-ounce, screw-capped bottles containing $1 \mathrm{ml}$ of nutrient broth. One of each set contained plain nutrient broth, the second nutrient broth and the broken-off stick and tip of a plain cotton-wool swab, and the third nutrient broth with the tip and stick of an albumen-coated swab. Surface viable counts were performed from the suspensions in these bottles at 1 and $2 \mathrm{~h}$.

Fate of S. pyogenes on swabs. Five of each of the two varieties of swab were loaded with standard (enumerated) inocula of $S$. pyogenes and plated directly on replicate blood-agar 
plates. The same swabs were then either agitated or squeezed by means of sterile forceps in $1-\mathrm{ml}$ volumes of nutrient broth. The swabs released material into the $1-\mathrm{ml}$ volumes of broth during this procedure, but in turn they took up some of the sterile broth; the amount of broth plus expressed material remaining at this stage ranged from $0.75-0.90 \mathrm{ml}$ and this contained the streptococci that were shed or expressed from the swab; $0 \cdot 1-\mathrm{ml}$ volumes were then removed and surface viable counts were performed. These counts were multiplied by the volume of nutrient broth, to obtain an estimate of the total number of $S$. pyogenes discharged. These data were then compared with the counts obtained initially from the swabs on direct plating.

Colony-forming units ranged from single organisms to short chains. Inocula were most commonly prepared from $10^{3}$ or $10^{4}$ dilutions of the parent cultures and gram films of these showed large numbers of individual streptococci and chains consisting of only $2-4$ cocci.

Statistical analysis included application of the $t$ test and analysis of variance.

\section{TABLE I}

Immediate recovery of Streptococcus pyogenes on solid media from albumencoated and plain cotton-wool swabs

\begin{tabular}{|c|c|c|c|c|c|}
\hline \multirow{2}{*}{ Type of swab } & \multirow{2}{*}{$\begin{array}{r}\text { Number of } \\
\text { experiments }\end{array}$} & \multicolumn{2}{|c|}{$\begin{array}{l}\text { Mean percentage } \\
\text { recovery }\end{array}$} & \multicolumn{2}{|c|}{$\begin{array}{l}\text { Range of percentage } \\
\text { recovery }\end{array}$} \\
\hline & & $\begin{array}{c}\text { First } \\
\text { platings }\end{array}$ & $\underset{1-4}{\text { Platings }}$ & $\begin{array}{c}\text { First } \\
\text { platings }\end{array}$ & $\begin{array}{c}\text { Platings } \\
1-4\end{array}$ \\
\hline Albumen & 59 & $8 \cdot 2$ & $6 \cdot 6$ & $2 \cdot 8-14 \cdot 8$ & $1 \cdot 9-12 \cdot 6$ \\
\hline Plain & 59 & $8 \cdot 3$ & $6 \cdot 5$ & $0 \cdot 8-15 \cdot 4$ & $0 \cdot 7-12 \cdot 0$ \\
\hline
\end{tabular}

TABLE II

Effect of time on recovery of $S$. pyogenes from albumen-coated and plain cotton-wool swabs held at room temperature

\begin{tabular}{l|ccccccc}
\hline Type of swab & $\begin{array}{ccccccc}\text { Number of } \\
\text { experiments }\end{array}$ & \multicolumn{4}{c}{ Mean percentage recovery at time (h) } \\
\cline { 2 - 6 } & & 0 & 4 & 8 & 24 & 48 \\
\hline Albumen & 30 & 5.3 & 2.5 & 2.6 & 2.5 & 0.7 \\
\hline Plain & 30 & 5.8 & 3.1 & 2.7 & 2.2 & 0.4 \\
\hline
\end{tabular}

\section{RESULTS}

Survival of $S$. pyogenes on swabs

The mean recovery rates (i.e. percentages of viable count of the standard inoculum) at $0 \mathrm{~h}$ from albumen-coated and plain cotton-wool swabs were similar; they were respectively 8.2 and $8.3 \%$ for first platings from each swab and 6.6 and $6.5 \%$ for platings $1-4$ combined. The percentage recovery from 
first platings ranged from 2.8 to 14.8 from the albumen-coated swabs and $0 \cdot 8-15.4$ from the plain; the percentage recovery from platings $1-4$ ranged from 1.9 to 12.6 from the albumen-coated swabs and $0.7-12.0$ from the plain (table I). Upper limits of the ranges of percentage recovery from platings 1-4 are less than those of first platings because the former are ranges of mean percentages for each quadruple observation. Mean counts of four platings were calculated for each swab because, whereas in most cases first platings produced the highest counts and second platings the next highest, this was not invariably so. There was no statistical difference between the results obtained from the two types of $\operatorname{swab}(t=0.466 ; \mathrm{df}=90 ; \mathrm{P}>5)$.

The effect of delay in plating the swabs is shown in table II. The greater the delay the less were the chances of recovery of the streptococci. Statistical analysis showed no differences between the results obtained with two varieties of swab in the total recovery rate $(t=4.12 ; \mathrm{df}=210 ; \mathrm{P}<0.01)$; and both types of swab produced an identical number of growths (9 of 30) at $48 \mathrm{~h}$. There was nevertheless a marked difference in the number of colonies obtained from each type depending on whether the inoculum was suspended in saline or saliva. Processing in saliva produced a recovery rate that was $1-2 \%$ greater than the rate for the saline series.

TABLE III

Recovery of $S$. pyogenes from albumen-coated and plain cotton-wool swabs held at $4^{\circ} \mathrm{C}$

\begin{tabular}{l|cccccccc}
\hline \multirow{2}{*}{ Type of swab } & $\begin{array}{c}\text { Number of } \\
\text { experiments }\end{array}$ & \multicolumn{6}{c}{ Mean percentage recovery at time (h) } \\
\cline { 3 - 9 } Albumen & 6 & 4 & 8 & 24 & 48 & 72 \\
\hline Plain & 6 & 7.5 & 8.3 & $7 \cdot 7$ & 5.7 & 5.1 & 6.6 \\
\hline
\end{tabular}

When the loaded swabs were held in their plastic containers for periods at $4^{\circ} \mathrm{C}$ before plating, the striking feature was the very small difference between the percentage recovery on plating at $0 \mathrm{~h}$ and that obtained after a delay of $72 \mathrm{~h}$ (table III). With swabs held at room temperature, the loss of viability of organisms was almost complete by $48 \mathrm{~h}$.

\section{Toxicity of cotton wool}

One of the explanations put forward for the dramatic fall in numbers on immediate plating was the possibility that cotton wool may contain factors toxic to streptococci. This was investigated in replicate studies (see Materials and Methods) by immersing the tips of albumen and plain swabs in small volumes of nutrient broth that contained known numbers of $S$. pyogenes and comparing viable counts after contact for $2 \mathrm{~h}$. Analysis of variance performed 
on logarithmic values demonstrated that there were no significant differences between the mean counts obtained from the control and test models, indicating that no demonstrable toxic effect was produced by the wool tips under these conditions.

\section{Fate of $S$. pyogenes on swabs}

Further experiments showed that at least one of the explanations for the loss of organisms on immediate plating was that the organisms were not released from the swab. When swabs loaded with standard inocula were plated directly, low counts were obtained, as in previous experiments; subsequent agitation of the swabs in broth yielded $c .53 \%$ recovery, and squeezing by forceps into broth gave $c .49 \%$ recovery, even though these swabs had first been used for direct plating. Albumen-coated and plain swabs gave similar results.

\section{Discussion}

Several reports have been published on the unpredictability of survival of $S$. pyogenes on cotton-wool swabs, and various explanations for this have been put forward. Rubbo and Benjamin in 1951 drew attention to variables such as numbers of organisms loaded on the swab, the type of wool used and the presence or absence of moisture. Dadd et al. (1970) suggested that this lack of predictability may be due in part to other factors, such as the strain of streptococcus used, the technique of preparing the inoculum and its distribution on the swab head. When these workers examined other types of fibre to assess whether any was consistently superior to cotton wool, none was found to be so.

In the present study, both plain and albumen-coated swabs were loaded with known numbers of $S$. pyogenes suspended in saliva or in saline. It is appreciated that this attempted simulation of natural circumstances may well be unsuccessful in that the organism may behave quite differently in vivo; there may be an important interplay of antibiotic, immunological, nutritional, physiological or physical factors that cannot be incorporated in any laboratory model.

When standard inocula of $S$. pyogenes were loaded on plain and albumen swabs and plated immediately, a mean recovery rate of around $8-9 \%$ colonyforming units was consistently produced from each of the 59 first platings. The mean of platings $1-4$ from 59 swabs was between 6 and $7 \%$, slightly less than the mean of the first platings. Collee et al. (1974) reported an even lower recovery rate of $3-5 \%$ in their similar studies on the recovery of anaerobes. In that study, and in the present study, the dramatic fall in numbers of organisms recovered cannot be primarily attributed to any toxic factors in the swab, as has been suggested by Hughes (1972). When standard inocula of $S$. pyogenes were exposed for up to $2 \mathrm{~h}$ in nutrient broth containing swab tips, there was no significant diminution in the viable counts obtained from the test models compared with those of the controls. A contact time of $2 \mathrm{~h}$ was used, since in previous studies all swabs taken from children were processed within this period (Ross, 1971a). It might be argued that the streptococci in suspension were not 
intimately in contact with a postulated insoluble toxic factor on the swab, but the further results indicate that there is a much more likely explanation.

When the swabs, having been plated on solid media, were agitated in $1 \mathrm{ml}$ of nutrient broth or were squeezed by a forceps in the same volume of broth, the numbers of viable organisms (colony-forming units) released were seven or eight times greater than those obtained on initial direct plating of the swabs. Thus, an explanation for the disappearance of the streptococci on direct plating is that the organisms are not released from the swabs, and this finding indicates that a large proportion of the normally retained streptococci were not inactivated although they had been in close contact with swab materials. Both plain and albumen swabs produced a similar picture, so the absorbent or nonabsorbent state does not appear to be important from the point of view of retention of organisms.

It is tempting to speculate that these findings have a bearing on the poor recovery of $\beta$-haemolytic streptococci experienced with throat swabs on direct plating from patients in comparison with the high recovery rate from saliva (Ross, 1971a). It might well be that retention of organisms on the swab, rather than the effect of any toxic factors, is of major importance.

An observation of some practical importance was the similarity in the performance of the plain and albumen swabs both in the number of viable organisms that could be recovered after various time intervals and in the number of swabs that supported growth. Although comparisons of results of various studies is hampered by the absence of uniformity in experimental procedures, such findings are at variance with those of Bartlett and Hughes (1969). It can be concluded that albumen-coated swabs are no more efficient than plain in isolating $S$. pyogenes in vitro at least when the latter are buffered in phosphate and not sterilised by $\gamma$ radiation.

Results from plain and albumen swabs were broadly in agreement, but there was a marked difference in numbers of streptococci recovered depending on whether the swabs, plain or albumen, were processed in saline or saliva. Counts from the latter were higher than those from the saline suspensions indicating that saliva exerted some protective effect.

Whether swabs were held at room temperature or at $4^{\circ} \mathrm{C}$ before plating affected the results significantly. Not only did swabs held at $4^{\circ} \mathrm{C}$ maintain a higher level of viability of streptococci at all times, but they also all produced growth even after being held in their containers for $72 \mathrm{~h}$ before plating. It has been common practice for several years to hold specimens of urine in a refrigerator to prevent multiplication of organisms if the specimens cannot be despatched to the laboratory immediately, and, from the above findings, it would also seem reasonable to recommend refrigeration of throat swabs if any delay is envisaged in transit to the laboratory. This, however, may only apply to the isolation of $S$. pyogenes.

It appears that throat swabs are rather insensitive tools. If the recovery rate of $S$. pyogenes from the throat is only of the order of $8 \%$ of the inoculum, it follows that there may be a certain threshold number of organisms before any will appear on solid media, particularly in mixed culture. The clinical 
case will probably produce the requisite numbers but the carrier may not, and consequently could be missed.

If carriers are to be screened, if a particular organism has to be looked for, of if the efficacy of chemotherapy has to be monitored, it would seem prudent to agitate the swab in a fluid medium on arrival at the laboratory (Collee et al., 1974). Alternatively, by the processing of actual secretions or pathological material from cases or carriers in addition to swabs-for example, saliva from cases of sore throat (Ross, 1971a)-pitfalls associated with the exclusive use of swabs may be largely avoided.

\section{SUMMARY}

Simulated throat swabs were prepared with known numbers of Streptococcus pyogenes; some were suspended in pasteurised human saliva and an equal number in saline. Two types of commercially available swabs were tested; these were composed of (1) plain, buffered, cotton wool, and (2) albumen-coated cotton wool.

The mean recovery rates of first platings on solid media from albumen-coated and plain cotton-wool swabs were similar $(8.2 \%$ and $8.3 \%)$ and the mean recovery rates from platings $1-4$ were also similar $(6 \cdot 6 \%$ and $6.5 \%)$.

The greater the delay in plating, the less were the chances of recovery of streptococci, although the viability of these was significantly prolonged on swabs held at $4^{\circ} \mathrm{C}$. Similar results were again produced by both types of swabs; processing swabs in saliva, however, produced a recovery rate that was $1-2 \%$ greater than the rate for the saline series.

Swabs were also agitated or squeezed by forceps in nutrient broth to release any organisms they contained, and standard samples of the broth were then plated on solid media. Counts thus obtained indicated that about $50 \%$ of the original inoculum was still viable and could be recovered from the broth; in comparison, recoveries from initial direct plating of the swabs were low. No demonstrable toxic effect was produced by the cotton wool in these experiments.

I am greatly indebted to Mrs Hannah Lough and Mrs Sandra Johnstone for expert technical assistance, to Professor J. Boyes for financial aid, to Mr W. Adams for statistical advice and to Professor J. G. Collee for interest and help.

\section{REFERENCES}

ANDERSON, K. F. 1965. Antibacterial bacteriological swabs. Br. med. J., 2, 1003.

Bartlett, D. I. ANd Hughes, M. H. 1969. Bacteriological swabs. Br. med. J., 3, 450.

British MEdical Journal (Leading ArTiCle). 1972. Streptococcal sore throat. 3, 132.

Cain, R. M. And SteEle, H. 1953. The use of calcium alginate soluble wool for the examination of cleansed eating utensils. Can. J. publ. Hlth, 44, 464.

Collee, J. G., Watt, B., Brown, R. AND Johnstone, S. 1974. The recovery of anaerobic bacteria from swabs. J. Hyg. Camb., 72, 339.

Cruickshank, R. 1953. Taking swabs. Br. med. J., 2, 1095.

Dadd, A. H., Dagnall, V. P., Everall, P. H. and Jones, A. C. 1970 . The survival of Streptococcus pyogenes on bacteriological swabs made from various fibres. J. med. Microbiol., 3, 561. 
Ellner, P. D. ANd Ellner, C. J. 1966. Survival of bacteria on swabs. J. Bact., 91, 905.

Hollinger, N. F. AND LindBerg, L. H. 1958. Delayed recovery of streptococci from throat swabs. Am. J. publ. Hlth, 48, 1162.

Hollinger, N. F. AND RANTZ, L. 1959. In pursuit of the streptococcus: newer techniques for their recovery and identification, and clinical implications. Pediatrics, Springfield, 24, 1112.

Holmes, M. C. AND LeRmit, A. 1955. Transport and enrichment media in the isolation of haemolytic streptococci from the upper respiratory tract. Mon. Bull. Minist. Hith, $14,97$.

Hughes, M. H. 1972. Streptococcal sore throat. Br. med. J., 3, 349.

MaIR, N. S. AND MCSwiggan, D. A. 1965. Antibacterial bacteriological swab. Br. med. J., $2,230$.

Mozziconacci, P., Gerbeaux, C., Caravano, R., Gerbeaux, S., Labonde, J., Rahman, S., RabCYNSKA, F., Orssaud, E. AND Virolleau, P. 1960. A study of group A hemolytic streptococcus carriers among school children. I. Material, methods, and results of the studies. Acta paediat., Stockh., 49, 711.

Pike, R. M. 1945. The isolation of hemolytic streptococci from throat swabs: experiments with sodium azide and crystal violet in enrichment broth. Am. J. Hyg., 41, 211.

Pollock, M. R. 1948. Unsaturated fatty acids in cotton wool plugs. Nature, Lond., 161, 853.

Ross, P. W. 1971a. Beta-haemolytic streptococci in saliva. J. Hyg., Camb., 69, 347.

Ross, P. W. 1971b. Throat swabs and swabbing technique. Practitioner, 207, 791.

RuBbo, S. D. AND Benjamin, M. 1951. Some observations on survival of pathogenic bacteria on cotton-wool swabs: development of a new type of swab. Br. med.J., 1, 983.

StuART, R. D. 1965. Transport problems in public health bacteriology. The use of transport media and other devices to maintain the viability of bacteria in specimens. Can. J. publ. Hlth, 47, 114.

WhITE, W. D. 1965. Antibacterial bacteriological swab. Br. med. J., 2, 229. 